\title{
Globalización e historia
}

\author{
[Globalization and History]
}

\author{
JOHANNES ROHBECK \\ Technische Universität Dresden \\ Johannes.Rohbeck@tu-dresden.de
}

\begin{abstract}
Resumen: La historia ocupa un papel marginal en las teorías actuales de la globalización. Esto no deja de sorprender, pues "globalización" es, en esencia, un concepto que describe un proceso de la historia. Menos aún se habla de la filosofía de la historia, sobre todo porque ha caído en descrédito. Sin embargo, casi todas las argumentaciones emplean modelos de interpretación propios de la filosofía de la historia. Se conjetura qué tendencias generales le son inherentes a la globalización y si apuntan a un "progreso" o a una "decadencia" de la civilización humana. Por último, el problema ético de la justicia global debe tomar en consideración el desarrollo de la historia acontecida. Estos temas dejan claro que el recurso a la historia con implicaciones filosóficas es imprescindible para resolver los problemas de la globalización.

Palabras clave: filosofía de la historia, historia global, espacio histórico, justicia global, deber global de auxilio
\end{abstract}

\begin{abstract}
Contemporary theories of globalisation seldom mention history. This is surprising, because "globalisation" is essentially a term describing an historical process. There is still less mention of the philosophy of history, especially due to the discredit cast upon it. And yet nearly all of the relevant arguments operate with patterns of interpretation borrowed from the philosophy of history. The authors speculate on which general tendencies are inherent to globalisation and whether they are more indicative of the "progress" or of the "downfall" of human civilisation. Finally, the ethical problem of global justice requires us to take into account the course of history thus far. These topics underline that resorting to history with all of its philosophical implications is essential if we are to resolve the problems caused by globalisation.
\end{abstract}

Key words: philosophy of history, global history, historical space, global justice, global obligation to assist

Si se analiza el fenómeno de la globalización desde una perspectiva filosófica, habría que constatar, en primer lugar, que lo global siempre ha sido un tema del que se ha ocupado la filosofía. Buscar los conceptos y principios universales que pueden considerarse válidos para la humanidad en su conjunto es parte de su tradición. Desde la Modernidad, los derechos humanos fundamentados en la filosofía tenían que valer de la misma manera para todos los habitantes de la Tierra. En especial, la filosofía de la historia constituida a partir de la Ilustración reclamó para

Diánoia, volumen LXIII, número 80 (mayo de 2018): pp. 119-147. 
sí el derecho a una historia universal o historia mundial en la que participaran todos los pueblos y culturas. Esto se aplica también a las filosofías de la historia posteriores aunque se distanciaran de la idea del progreso y la teleología, e incluso a la posición ya más tardía de la poshistoria, en la que se apreciaba un "final" de la historia en su conjunto.

En las teorías actuales de la globalización la historia no se tematiza más que en raras ocasiones. Menos aún se habla de la filosofía de la historia, sobre todo porque esta disciplina ha caído en descrédito. Sin embargo, si se analizan con detenimiento esas teorías, se comprobará que casi todas las argumentaciones emplean, de manera más o menos explícita, modelos de interpretación propios de la filosofía de la historia. Los autores conjeturan sobre qué tendencias generales pueden reconocerse en la globalización, cuáles le son inherentes y si apuntan hacia un "progreso" o a una "decadencia" de la civilización humana. Además, las preguntas por el momento histórico a partir del cual se podría hablar ya de globalización, por lo "nuevo" en el estado actual de la globalidad que se ha alcanzado, así como por los desarrollos que se han de esperar en el futuro, son imposibles de responder sin una reflexión sobre la historia.

Con esta perspectiva histórica global la imagen de la historia se transforma de nuevo. En las teorías tradicionales de la historia se subrayaba el tiempo histórico, cuyos conceptos y estructuras se investigaban. La historia se equiparaba con la "temporalización". Así, se han realizado investigaciones sobre los tiempos históricos, con sus continuidades y rupturas, además de los tiempos cambiantes como el estancamiento y la aceleración. En el contexto de la globalización los espacios históricos adquieren una importancia creciente, de tal manera que la historia no sólo se "temporaliza", sino que también se "espacializa". Mediante el análisis de cómo se han creado con el paso del tiempo los diferentes espacios económicos, políticos, sociales y culturales, la historia aparece como una configuración espacio-temporal.

Si se analiza con mayor detalle el contenido de las tendencias de la globalización, surge la pregunta por las fuerzas motrices esenciales de ellas y cómo se relacionan entre sí. Según la interpretación materialista de la historia, los factores económicos, técnicos y políticos son especialmente determinantes. Por su parte, la variante idealista privilegia los factores culturales y comunicativos. Asimismo, se aborda la pregunta de si son actores individuales o, más bien, colectivos los que desempeñan el papel principal. Por último, si se presupone que la globalización es una formación histórica, surge la pregunta contraria, a saber, ¿qué consecuencias tiene este proceso para la situación social, política y cul- 
tural de mujeres y hombres? Junto a la crisis ecológica, el problema más grave es la pobreza mundial. En este punto se entrecruzan ambos problemas. Se puede decir que el calentamiento del planeta amenaza a toda la humanidad. No obstante, si se analiza el asunto con mayor detenimiento, se aprecia que los pobres se ven más afectados que los ricos: mientras que los países pobres del sur padecen altas temperaturas y sequías, los países ricos pueden incluso aprovecharse de ello, y llegamos así a la cuestión ética de la justicia global.

Mi tesis es que la ética de la globalización necesita una reflexión propia de la historiografía y de la filosofía de la historia, ya que no cabe duda de que las catástrofes climáticas y la pobreza global, que en parte guardan relación entre sí, las han "provocado" las personas. De ahí hay que extraer una consecuencia ética: que los daños provocados deben repararse con medidas compensatorias. El debate actual sobre estas medidas muestra el papel central que en él desempeña el vínculo con la historia. Aquellos que, por lo general, no aceptan que exista un deber de los países industrializados con los países pobres, consideran que el contexto histórico es irrelevante. Pero tampoco quienes están conscientes de la obligación de ayudar que tienen los países ricos fundamentan ese deber de auxilio con la historia. Sin embargo, una responsabilidad de largo alcance sobre este asunto y que incluya una compensación por las consecuencias de un comportamiento dañino sólo se puede fundamentar si se apela a la historia acontecida. De aquí se sigue que el recurso a la historia con implicaciones específicas para la filosofía de la historia es imprescindible para orientarnos en la acción práctica del presente con vistas al futuro y, con ello, al bienestar de las generaciones venideras. De ahí que llame a este tipo de deber "responsabilidad histórica".

\section{Filosofía de la historia y teoría de la globalización}

La globalización y la filosofía se relacionan en la medida en que la segunda hace uso desde sus orígenes de la perspectiva global. Fue sobre todo en el siglo XVII cuando la filosofía, con sus diferentes sistemas metafísicos, se centró en el mundo en su totalidad. Mientras que en la cosmología se mesuraba la totalidad del universo, en la filosofía política se fundamentaba un derecho natural con validez universal. En la teoría general del conocimiento se creía estar en posesión de la verdad universal. También en el siglo XVIII estaba extendida la perspectiva global, acompañada de una cosmología que tendía al materialismo y una antropología cada vez más relevante, y que llegó incluso a proponer ciertas características aplicables a todos los seres humanos. A estas discipli- 
nas hay que sumarles una nueva: la filosofía de la historia, que desde un principio se concibió como la historia del género humano. En este sentido, se puede observar que la filosofía ha contribuido con su pretensión de universalidad al surgimiento de la idea de globalización (Figueroa 2004, p. 9; cfr. Negt 2001, pp. 42 y ss.; Toulmin 1994, p. 281).

Con todo, es necesario trazar distinciones más precisas, ya que con la filosofía de la historia que se constituyó por la mitad del siglo XVIII surge un paradigma nuevo por completo. Como consecuencia de la historización del ser humano y de su mundo, también lo global se concibió como un proceso histórico que comenzó en el pasado, continúa en el presente y del que se puede esperar que prosiga en el futuro, si bien su final sigue abierto. La unidad de la humanidad ya no se presuponía de manera abstracta, sino que se entendía como un desarrollo de la interacción creciente entre los diferentes pueblos y culturas y, en la medida en que se descubrieron culturas lejanas, se reconoció en líneas generales la diversidad de las culturas del mundo que interactúan las unas con las otras. En definitiva, si la globalización es en esencia un concepto histórico, la filosofía de la historia representa el primer desarrollo teórico de la globalización.

En su aplicación, el concepto de historia universal se muestra menos universal y armónico de lo que pudiese parecer en principio. Así, en su "Plan de deux discours sur l'histoire universelle", Anne Robert Jacques Turgot no albergaba ninguna duda de que en la historia de la humanidad lo que hay que narrar son, sobre todo, guerras, esclavitudes y liberaciones violentas (Turgot 1913, p. 283). Al mismo tiempo, intentó probar que, en el proceso contingente de la historia, la civilización no desaparece sin dejar rastro alguno, sino que permanece gracias al intercambio recíproco con las culturas de los diferentes pueblos, intercambios que o bien son impuestos o bien son aceptados.

La idea de una historia universal tomó una forma concreta muy similar en la Histoire des deux Indes que Guillaume Raynal y Denis Diderot redactaron juntos (Raynal y Diderot 2001). El material diverso no quedaba unido por ninguna idea sistemática externa, sino que el hilo conductor de la argumentación integraba la historia de los descubrimientos y las conquistas de Asia y Sudamérica, el Caribe, África y, por último, Norteamérica — una historia que, entretanto, abarca ya toda la Tierra y conecta entre sí casi todas las culturas del mundo-. Ninguna totalidad se daba por supuesta, sino que se describía el acercamiento paulatino entre los pueblos.

En Alemania fueron sobre todo los ilustrados de Gotinga quienes se hicieron cargo del proyecto de una historia universal. Un ejemplo es 
August Ludwig von Schlözer y su Universalhistorie. Para él la historia universal era una "auténtica historia de la humanidad que instruía mediante ejemplos sobre su comienzo, transcurso, ennoblecimiento y degeneración". Sobre el "concepto de una historia mundial sistemática", Schlözer escribió:

Queremos comprender en su totalidad las revoluciones de la Tierra (que habitamos) y del género humano (al que pertenecemos) para reconocer el estado actual de ambos fundamentos. Queremos investigar las causas y consecuencias de la historia de la humanidad en Oriente y Occidente - en ambos lados de la línea divisoria- y de su sucesivo comienzo, ennoblecimiento y decadencia en todas sus formas: de país en país, de pueblo en pueblo, de época en época. (Schlözer 1772, p. 2)

Schlözer no sólo defendía de manera explícita el perfeccionamiento, sino que aceptaba también la degradación. En ningún caso se trataba de una creencia ingenua en el progreso.

En esta tradición se encontraba también Hegel, quien sólo reconocía la historia como "filosófica" cuando se concebía como "historia mundial" (Hegel 1970, p. 14). Dado que, en última instancia, Hegel omite el tiempo en su modelo de desarrollo, es el espacio geográfico el que adquiere la mayor relevancia para él. Los presupuestos empíricos se orientan sobre todo a países y continentes, como la división en un "mundo" oriental, griego, romano y germánico. Al igual que Raynal y Diderot, Hegel interpretó el "espíritu del mundo" como si caminase por lugares y épocas, y asignó una posición de liderazgo a los pueblos correspondientes, de manera que la "antorcha del progreso" pasaba de una nación a otra en el transcurso de las glorias y decadencias que transitaban cada una de ellas. Sin embargo, mientras que hacia el final del siglo XVIII los representantes de la Ilustración ya tenían la mirada puesta en Norteamérica como la nueva cima, Hegel, a pesar de tener un presentimiento similar, se aferraba a la supremacía de Europa.

Karl Marx vio el fundamento para una universalización de la historia no en el "espíritu del mundo", sino en el "mercado mundial" y la distribución del trabajo a escala internacional. Incluso considera al mercado mundial como el verdadero núcleo del espíritu del mundo hegeliano:

En la historia anterior es, por lo demás, un hecho empírico el que los individuos concretos, al extenderse sus actividades hasta un plano históricouniversal, se ven cada vez más sometidos a un poder extraño (cuya opresión toman luego como una cortapisa del llamado espíritu universal, etc.), 
poder que adquiere un carácter cada vez más de masa y se revela en última instancia como el mercado mundial. (Marx y Engels 1958, p. 37)

El postulado de la alienación oculta las relaciones concretas de cooperación que investigaba Marx, relaciones que adoptaban dimensiones de la historia universal:

Cuanto más se extiendan en el curso de esta evolución los círculos concretos que influyen los unos en los otros, cuanto más se vea el aislamiento primitivo de las diferentes nacionalidades destruido por el desarrollo del modo de producción, del intercambio y de la división del trabajo que ello hace surgir por vía natural entre las diversas naciones, tanto más se convierte la historia en historia mundial, y así vemos que cuando, por ejemplo, se inventa hoy una máquina en Inglaterra, son lanzados a la calle incontables obreros en la India y en China y se estremece toda la forma de existencia de estos países, lo que quiere decir que aquella invención constituye un hecho histórico-universal. (Marx y Engels 1958, pp. 45-46)

Con este análisis, Marx se revela como uno de los primeros teóricos de la globalización.

La idea de una historia universal ha adquirido una actualidad inesperada gracias a la tendencia contemporánea de la globalización. Del mismo modo que el campo de acción de los seres humanos se vuelve cada vez más amplio, las ideas de "un mundo", de la sociedad global y de la historia universal han ido tomando una forma concreta; de ahí que estén a punto de convertirse en una realidad histórica. Como contraparte se plantea la pregunta sobre la posibilidad de considerar la "historia universal" y la "globalización" como sinónimos o, por el contrario, de abandonar ambas categorías debido a su cercanía excesiva.

Tal distanciamiento demuestra que hay voces escépticas que, por razones críticas e ideológicas, cuestionan el concepto de globalización, pues parece rehabilitar la antigua filosofía de la historia y, por consiguiente, el "espíritu del mundo" hegeliano —una filosofía de la historia blanco de conocidos reproches: que no es más que una historia salvífica secularizada; que se erige sobre presupuestos metafísicos dudosos; que no ha sido demostrada científicamente o que difunde un universalismo, un eurocentrismo y una creencia en el progreso que son inadmisibles (Brauer 2016, pp. 51 y ss.) - . De este modo se entiende también el argumento para distinguir entre "historia universal" e "historia global": mientras que la antigua filosofía de la historia mundial se consideraba teleológica y determinista, el concepto de historia global ofrece 
la oportunidad de ocuparse de un proceso tan complejo como el de la globalización de una manera empírica y diferenciada (Belvedresi 2012, pp. 63-64; Acha 2016, pp. 164 y ss.). Como puse de manifiesto en un breve bosquejo ( $c f r$. Rohbeck 2000, pp. 25 y ss.; Rohbeck 2010, pp. 54 y ss.), puesto que no comparto ninguno de estos prejuicios que acabo de mencionar, considero preferible (véanse también Roldán 2012, pp. 83-84; D’Aprile 2012, p. 123) analizar el proceso de la globalización a partir de la filosofía "clásica" de la historia, desde la Ilustración europea hasta Marx.

Quien considere que el concepto de globalización o historia global posee cierta connotación "naturalista" por contener el término "globo", podría preferir el neologismo "mundialización" para referirse al mundo "creado" por el hombre (Negt 2001, p. 37; Haug 2003, pp. 207208). Sin embargo, ése es justo el sentido del concepto tradicional de historia mundial que contiene también la concepción filosófica genuina del mundo. De un modo similar se puede defender el concepto de historia universal: mientras que la "globalización" se asocia con el capitalismo que se expande de manera natural, la idea de universalidad recuerda a la tradición de los derechos a la libertad que, no olvidemos, estaban ya presentes en la filosofía de la historia: "La globalización del intercambio pone fin a la universalización de los valores" (Baudrillard 2007, pp. 36-37). Entretanto el concepto "planeta" se adecua para caracterizar la historia del cosmopolitismo, de manera que se puede hablar de una "planetary history" (Antweiler 2011, p. 69; D'Aprile 2012, p. 124). Sin embargo, el uso del concepto de globalización excluye esta crítica. Al fin y al cabo, este concepto ya implantado en nuestro lenguaje tiene la ventaja de que pone de relieve - frente a los siglos XVIII y XIXlo históricamente nuevo en el proceso histórico mundial.

\section{La globalización como proceso histórico}

Al concebir la globalización como un proceso histórico, surge primero la pregunta sobre su inicio y sus transformaciones. En otras palabras, ¿qué es lo realmente nuevo en la globalización? De la respuesta dependerá qué es lo que hay que entender por globalización. Aquí se muestra que la perspectiva histórica resulta esencial para caracterizar la globalización y, si se trata de las categorías aplicadas, la filosofía de la historia también puede sernos útil, ya que es capaz de analizar los modelos de interpretación más o menos explícitos en los discursos sobre la globalización. 
Las respuestas a la pregunta “¿qué es lo nuevo?” son de lo más diversas, y van desde la negación radical hasta la afirmación enfática. A grandes rasgos se pueden distinguir tres posiciones. La primera niega lo novedoso de la globalización y afirma que lo que se describe con este concepto se desarrolló hace ya mucho tiempo. De aquí se desprende que los imperios de carácter global, los mercados y el comercio internacional han existido desde la Antigüedad y la Edad Media. Sin embargo, si suponemos que la globalización es, en el fondo, un fenómeno atemporal, sin historia, se sigue que su existencia no es, en modo alguno, la de una formación histórica específica. Si esto fuera realmente así, del concepto de globalización no quedaría más que lo que queda de una expresión de moda, una mera ideología o un mito moderno (Jameson 1998, p. 55; Hirst y Thompson 2005, p. 98; Groß 2007, p. 11).

La segunda posición acepta que el proceso de globalización ha producido algo nuevo. Pero lo innovador consistiría sin más en un crecimiento cuantitativo, esto es, en una condensación gradual de interdependencias económicas y comunicativas. Con la transición del mercado al espacio global, el capitalismo alcanza su último y más alto estadio. En este caso sí que tiene lugar la historia, pero sólo como un continuo homogéneo. $\mathrm{Y}$, puesto que la historia ya no produce nada nuevo, lo que se avecina es un supuesto "final de la historia", con lo que la teoría de la globalización se transforma en poshistoria (Jameson 1998, p. 55; Kohler 2005, p. 165; Darwin 2009, p. 49).

La tercera posición considera que la globalización es un estadio cualitativamente nuevo de la historia. Aunque no ha surgido de la nada y tiene en efecto raíces históricas, la globalización puede plantear algo realmente nuevo. Por ejemplo, el carácter multinacional del capitalismo, los sistemas globales y una política transnacional. En este caso se trata de un proceso histórico de transformaciones técnicas, económicas, políticas y culturales que contiene tanto continuidades como discontinuidades y que en modo alguno puede considerarse cerrado (Keohane y Nye 2005, p. 75).

Merece la pena detenernos en esta tercera posición. En un primer momento, debemos diferenciar los elementos de la globalización que ya pueden considerarse antiguos e identificar cuál ha sido la base para construir su nueva forma. Después, hay que enfocar la atención en los cambios que ha sufrido la globalización para determinar el fenómeno en su sentido actual. Hasta que no se lleven a cabo estas diferenciaciones históricas no será posible dar una forma actual y sustanciosa al concepto de globalización. 
Si se revisa la historia de la globalización, se ha de dar crédito a la observación de algunos autores según la cual la interdependencia global en los ámbitos económico, militar, social y cultural existía ya con anterioridad. Como consecuencia de los viajes de exploración y las colonizaciones que tuvieron lugar entre los siglos XVI y XVIII comenzó a extenderse la idea de una humanidad global (Figueroa 2004, p. 12, Antweiler 2011, p. 122). Al surgir relaciones que iban más allá de las fronteras establecidas, hubo que darles una forma jurídica y trazar un orden jurídico global (Höffe 1999, pp. 58 y ss.). En el terreno económico la globalización se desarrolló sobre todo desde la mitad del siglo XIX hasta la Primera Guerra Mundial (Keohane y Nye 2005, p. 75). Al mismo tiempo, la globalización de la comunicación se inició con la invención del telégrafo y del teléfono, algo que se puso de manifiesto con la instalación de cables telegráficos transatlánticos entre Europa y América.

Sin embargo, los autores que enfatizan los elementos potenciales de innovación de la globalización atribuyen valor al hecho de que este proceso no apareció como tal sino hasta el siglo xx. No fue sino hasta después de la Segunda Guerra Mundial cuando apareció por primera vez una red global que posibilitó la interacción directa a distancias multicontinentales sin barreras ni controles (Negt 2001, p. 36; Lübbe 2005, p. 122; Giddens 2005, p. 60). De este modo, la comunicación se densificó y aceleró a la vez que se volvió más intensa y profunda. Esto no afectó sólo a las noticias, sino también a la densidad, velocidad e intensidad con las que interactúan las instituciones (Keohane y Nye 2005, p. 78). Así es como cooperan las organizaciones transnacionales y supraterritoriales que comienzan a formar un sistema político mundial que rebasa el tejido de las relaciones internacionales. A esto hay que añadir las migraciones, sin dejar de incluir el lado negativo del terrorismo global (Negt 2001, p. 87; Giddens 2005, p. 62; Cheneval 2005, p. 187). Lo nuevo en la economía es la creación de un mercado financiero global que se desarrolla con relativa independencia de la circulación de mercancías y que ha conducido a sus respectivas crisis. En tiempos recientes, la producción global está sobrepasando la división internacional del trabajo en la medida en que se crean productos comunes en lugares muy distantes (Hardt y Negri 2001, pp. 289-290; Scholte 2005, pp. 159 y ss.).

En la comparación entre las posiciones citadas queda de manifiesto que una determinación de aquello que hoy en día podríamos llamar "globalización" sólo puede lograrse desde una perspectiva histórica. Un enfoque como éste nos permite evitar también un error al que se le debería prestar más atención, a saber, el de resaltar y absolutizar 
aspectos o acontecimientos individuales. Un ejemplo de ello es internet. Por el contrario, la globalización tiene más sentido si se concibe como una época histórica novedosa y compleja.

En el contexto de estos planteamientos, que aún han de exponerse con mayor detalle, se puede observar que algunos autores ofrecen modelos de las fases históricas de la globalización. El modelo "clásico" establece cuatro etapas. La primera de ellas hace referencia a la existencia de imperios parciales en la Antigüedad y la Edad Media, la segunda al comienzo de los viajes de exploración y de las colonizaciones que tuvieron lugar entre los siglos XVI y XVIII, la tercera al surgimiento en el siglo XVIII de un mercado mundial con la sistematización de la colonización y el imperialismo, y la cuarta etapa se refiere a la compresión del espacio y el tiempo mediante las redes electrónicas (Figueroa 2004, p. 13; cfr. Scholte 2005, p. 85).

Otro modelo funciona de manera típica al distinguir determinados tipos de globalización en la secuencia temporal. De ahí que la primera fase consista en la construcción de lo nacional con Francia como ejemplo, la segunda en el surgimiento de lo global gracias al capitalismo industrial británico y al colonialismo, y la tercera y última fase en la formación de lo global como un sistema transnacional (Sassen 2008, pp. 35 y ss.). Para Latinoamérica se bosqueja la siguiente periodización: 1) poblamiento originario de América; 2) imperialismo y colonización; 3) lucha por la independencia y fundación de los Estados nacionales; 4) surgimiento de las dictaduras militares, y 5) tendencia al turbocapitalismo (Acha 2016, pp. 179-181).

Estos modelos graduales, que recuerdan a la filosofía de la historia de la época ilustrada, plantean la pregunta por la progresión general de la historia. ¿Consisten sus etapas en un continuo o lo que la caracteriza son las rupturas históricas?

Si se toma como ejemplo la historia de la Comunidad Europea, puede apreciarse que las etapas que van desde la formación de los Estados nacionales hasta la pretendida integración política son susceptibles de representarse como un desarrollo continuo. Según este presupuesto, de esa integración resulta un fracaso en cuanto "error de la historia" (Cheneval 2005, p. 199; Habermas 2011, p. 39). Esto presupone una vez más que, además de la historia que ha conducido al "error", podría existir un camino regular o predeterminado de ella. También el desarrollo de los Estados nacionales hacia una república mundial de carácter federal, claramente diferenciada de un Estado mundial homogéneo, se deja analizar como una tendencia lineal de ese tipo que potencialmente podría realizarse (Höffe 1999, pp. 267 y ss.; Habermas 2011, p. 82). 
Por último, la expansión del mercado mundial y el intercambio de datos cada vez más hermético y acelerado también se pueden interpretar como un incremento continuo de lo global.

También en estos modelos lineares se manifiesta la crítica. Frente a las supuestas continuidades, la globalización ha quedado marcada como la ruptura histórica con la cultura occidental (Touraine 2007, p. 246). Mediante la tecnificación y economización total se destruyen culturas tradicionales sin que se ponga una nueva cultura en el lugar que queda vacío (Kehoane y Nye 2005, p. 76). Fundamentalmente se posicionan contra la teoría de la globalización que se apoya demasiado en la teoría de la modernización (Hardt y Negri 2001, p. 284; Giddens 2005, p. 60; y, en la posición contraria, Pohlmann 2006, p. 166; Jameson 1998, p. 61). Mientras que a las teorías de la modernización se les puede reprochar que, a fin de cuentas, presentan el proceso de civilización como un desarrollo exitoso, una teoría de la globalización que se distancie de este extremo tiene la oportunidad, y también la fuerza destructiva, de analizar las turbulencias sociales y los daños culturales. En este sentido, la teoría de la globalización podría cumplir una función crítica.

Más allá de las teorías de continuidades y discontinuidades, la teoría de las transformaciones históricas desempeña un papel mediador (Sassen 2008, pp. 17 y ss.). Al concebir el proceso de la globalización como una transformación, se pueden caracterizar las transiciones de las fases más primitivas hasta la situación actual como una secuencia de cambios profundos en los que lo pasado se transforma en lo presente. Los conceptos de lo potencial y del cambio repentino son las categorías que permiten una descripción de este tipo. De ahí que lo nuevo no surja simplemente de la aniquilación del orden precedente, sino que, por el contrario, los viejos potenciales tales como los tradicionales Estados nacionales son los que abren nuevos horizontes para la producción de nuevos órdenes (Sassen 2008, p. 28). Los llamados puntos de cambio radical existen, por ejemplo, cuando una época que se caracteriza por el Estado nacional desemboca en un periodo en el que los órdenes políticos se multiplican y diferencian (Sassen 2008, p. 30). Lo importante en este contexto es que los antiguos Estados nacionales no desaparecen sin más, sino que establecen nuevos órdenes políticos junto a sí mismos, e incluso dentro de ellos. Las categorías de lo potencial y del cambio repentino significan también que las formas antiguas y nuevas existen al mismo tiempo, constituyendo ensamblajes o formas híbridas (Sassen 2008, p. 642). En términos de la filosofía de la historia, nos encontramos aquí con la contemporaneidad de lo no contemporáneo. 
Si se profundiza en estas concepciones sobre la progresión de la historia, se muestra que hay tras ellas valoraciones divergentes. Aquellas que, en la línea de las teorías de la modernización, caracterizan la globalización más bien como un proceso constante, tienden a valorar este desarrollo como un "progreso". Por progreso entienden las innovaciones en la comunicación técnica mediada, en el comercio global, en la producción transnacional y en el surgimiento de instituciones supranacionales (Scholte 2005, pp. 49 y ss.). Por el contrario, quienes ponen más énfasis en las rupturas históricas critican la globalización por considerarla un proceso que amenaza y destruye las culturas históricamente consolidadas (Groß 2007, p. 16). Desde esta perspectiva, la globalización representa menos una flecha ascendente que una espiral descendiente o una tendencia regresiva (Baudrillard 2007, p. 41; Pohlmann 2006, p. 176). En estas observaciones se confirma que las teorías de la globalización emplean, ya sea de manera explícita o implícita, esquemas de interpretación de lo histórico.

\section{Espacios y tiempos globales}

La percepción del espacio ha cambiado como consecuencia de la globalización. Todo el globo se ha transformado en un espacio de experiencia comprehensivo. Y, dado que el espacio global ha surgido de la historia, se puede hablar también de un espacio histórico novedoso o de una espacialización de la historia. En las ciencias históricas se habla desde hace unos treinta años del "spatial turn" (Osterhammel 1998, p. 374; Schlögel 2003, pp. 12-13). Los estudiosos ven en la historia mundial una forma de análisis que cada vez adquiere más actualidad y que tiene por objeto contextos amplios de acción. El objetivo es la investigación de las relaciones y de los procesos de transferencias interculturales en el espacio histórico; por ejemplo, las migraciones, las conquistas, los movimientos colonizadores y las transferencias culturales. En este contexto ha surgido el concepto de una nueva "world history" o "global history" (McNeill 1982, p. 75). Al igual que la perspectiva propia de la filosofía de la historia puede servir para el análisis de la globalización, ahora vemos como, a la inversa, la experiencia con la globalización influye en la filosofía de la historia. Por supuesto, en estas observaciones hay que evitar algunos malentendidos.

En primer lugar, no se debe entender en modo alguno que por la espacialización de la historia la referencia al tiempo se sustituya con la relación espacial (por ejemplo, Pohlmann 2006, p. 166), aunque desde luego pueda dar esa impresión si se tienen en cuenta los desa- 
rrollos recientes del pensamiento histórico. El tiempo ocupó el lugar central con el interés creciente por la teoría de la historia en la segunda mitad del siglo Xx. El tema dominante consistía en las estructuras temporales de la historia o la semántica de los tiempos históricos (un buen ejemplo de ello es Koselleck 1979). Esta tendencia se confirma en la narratología, que abordó la narración histórica sobre todo como un problema temporal (Ricœur 1983). Hasta tal punto parecía que la historización era idéntica a la temporalización que el tiempo y la historia se consideraban casi sinónimos. Hay que tener en cuenta que acentuar la dimensión espacial de la historia no tiene como consecuencia una sustitución, pues el espacio y el tiempo históricos forman, sin duda alguna, una relación constitutiva (Koselleck 2000, pp. 78 y ss.). Si las acciones humanas constituyen la historia y la historiografía se encarga de narrar acciones, parece obvio que las acciones de los hombres sólo son posibles en el espacio y en el tiempo. Las relaciones espacio-tiempo crean las condiciones para las historias posibles.

Otro malentendido consiste en afirmar la "desaparición del espacio" o la aparición de una nueva "atopía” (Negt 2001, p. 40, critica esto). Detrás de estas afirmaciones se esconden experiencias con las tecnologías modernas. "Destrucción del espacio": tal era la divisa con que se describía ya en el siglo XIX el impacto del ferrocarril y con la que también se caracterizaban las consecuencias de los nuevos medios de transporte y comunicación del siglo $\mathrm{xx}$, como los coches y aviones, y también el telégrafo, el teléfono y la internet (McLuhan 1995, p. 149; Virilio 1990, pp. 126-127; Baudrillard 2007, p. 40). Esta idea se relaciona en forma estrecha con la velocidad que aumenta permanentemente y que afecta de manera directa a los medios mencionados. Las distancias se recorren cada vez en menor tiempo y se puede recorrer un trayecto mucho mayor en el mismo tiempo. La rápida superación de las distancias espaciales aparece, pues, como la aniquilación del espacio. Pero, entretanto, se ha demostrado que esta idea es falsa (Giddens 2005, p. 63), porque la comunicación no se desarrolla sólo en las autopistas de la información. Así, el desarrollo del transporte y de las comunicaciones demuestra la magnitud de los espacios que han de superarse en términos reales. Las recientes catástrofes naturales, así como las guerras que se libran actualmente, ponen de manifiesto la importancia que ha adquirido el transporte de bienes y de seres humanos entre distancias largas. Con la experiencia cada vez más concreta de la globalización económica, política y cultural se relativiza la tesis inicial según la cual las nuevas técnicas de comunicación conducen a la destrucción del espacio. En lugar de esto, se debería hablar más bien de una compresión del espacio. 
Si se considera en particular la tendencia a la espacialización de la historia, se debe diferenciar entre varios ámbitos en el proceso de la globalización. En especial, la economía y la política son las que poseen sus propias dimensiones espaciales.

Si partimos con Marx de la opinión de que el problema de la sobreacumulación es inherente al capitalismo, resultan ciertas consecuencias para su extensión geográfica (Hardt y Negri 2001, p. 222; Harvey 2003, pp. 87 y ss.). La forma de producción capitalista tiende a aumentar la producción de mercancías de manera permanente, como si en el mercado se le pudiera dar salida a toda ella. Así es como surge el excedente de capital, el cual no encuentra ningún uso y provoca que la tasa de beneficio caiga tendencialmente, sin olvidar que también aparece así la fuerza de trabajo excedente, lo que a su vez provoca que el desempleo sea, del mismo modo, un síntoma persistente. De esta manera, el capitalismo conlleva crisis duraderas que, dentro de un territorio limitado, son imposibles de impedir o superar. Aquí se muestra una contradicción entre la fijación con los Estados nacionales y la dinámica de la acumulación capitalista. El espacio limitado y las crisis económicas se condicionan en forma mutua.

Para salvar este problema crónico, a los empresarios capitalistas les queda el recurso de abandonar el territorio y ampliar su campo de acción (Harvey 2003, p. 94). Para ello tienen que sondear dónde se encuentran los mercados para dar salida al excedente de mercancías, dónde están las materias primas más rentables y la mano de obra más barata. El capital busca ventajas competitivas en los lugares con costos bajos y tasas altas de beneficio. Aquí hay que tener en cuenta no sólo la circulación internacional de las mercancías y la división internacional del trabajo, sino también, como se consideró antes, una producción globalizada de artículos individualizados que se pueden elaborar en lugares muy distantes los unos de los otros (Scholte 2005, p. 159). Esta reciente exploración de las condiciones novedosas de aprovechamiento se caracteriza por las nuevas "fijaciones espacio-temporales" (Harvey 2003, p. 87; Negt 2001, p. 72). Tienen lugar cambios de ubicación con movimientos espaciales que se entrecruzan y que en ningún modo se llevan a cabo de manera uniforme, sino que se concentran en determinados lugares que a menudo ofrecen ventajas monopolistas. El capital circula en el espacio y el tiempo, crea constantemente nuevos espacios económicos y produce su propia geografía histórica.

Esta economía del espacio se ha vuelto posible gracias a las nuevas tecnologías de la comunicación y del transporte que han transformado las condiciones de espacialidad. Mientras que, por un lado, desapa- 
recen las antiguas barreras locales, por otro, se condensan las relaciones temporales. Con las redes de ferrocarril, las vialidades, los aeropuertos y las instalaciones portuarias surge una nueva infraestructura que permite movimientos espaciales fluidos. En contraste, las oportunidades en los nuevos territorios devalúan los capitales en las antiguas regiones. De este modo se impone una lógica económica degenerada contra el poder político territorial. En este punto se puede constatar una interacción que consiste en que, de la misma manera en que el capitalismo produce espacios históricos y geográficos amplios, los nuevos espacios técnicos puestos en franquía dan forma al capitalismo.

En contra de esta tecnificación y economización se han desatado numerosas protestas. Se critica que los mercados globales escapen a los gobiernos y creen un desequilibrio entre la economía y la política, de modo que entre el crecimiento técnico y económico de la sociedad mundial y la fragmentación política y cultural del mundo se crea una relación tensa (Lübbe 2005, pp. 80-81; Habermas 2011, p. 42). Para ofrecer un contrapeso a esta situación hay que recuperar lo político.

Un paso representativo en esta dirección es la Unión Europea, que debe pasar de una mera comunidad económica a una unión política, a la cual le es propia también un gobierno económico europeo (Habermas 2011, p. 45). El error en la construcción llevada a cabo hasta el momento reside en la falta de mando político de la unión monetaria y en el carácter no democrático de los acuerdos de los jefes de gobierno. Para lograr una Europa que sea capaz de actuar en el terreno político y que se legitime democráticamente, las competencias políticas no sólo han de abarcar el territorio nacional, sino que han de hacerse extensivas al ámbito europeo. La tarea consiste en trabajar en un federalismo ejecutivo. En este caso los Estados nacionales desempeñarán aún el papel decisivo de un Estado miembro como garantes del derecho y la libertad pero, al mismo tiempo, tendrán que entregar parte de su soberanía al gobierno europeo. De este modo, la capacidad de actuación política se amplía más allá de las fronteras nacionales.

Un proyecto de globalización de mayor alcance tiene como objetivo una república mundial de carácter federal (Höffe 1999, p. 296). Con ello no se aspira a un Estado mundial global y homogéneo que ocupe el lugar de los Estados individuales, sino que, por el contrario, se aspira a que estos Estados conserven su legitimidad y sus derechos. Lo que se exige es un orden jurídico y estatal de carácter global que pueda garantizar la democracia universal y la paz global. A esto hay que añadir el cometido de velar por los principios de una justicia global, por un espíritu cultural con amplitud de miras y por un universalismo 
culturalmente abierto. Dado que los principios universales no pueden quedar completamente determinados, permiten garantizar la diversidad de democracias, cada una con su concreción histórica específica (Höffe 1999, p. 169). Una república como ésta sería responsable de la coexistencia jurídica entre Estados y sujetos no estatales. El contrato del Estado mundial tiene una legitimación combinada: por una parte, el contrato social internacional entre Estados particulares; por otra, el contrato social cosmopolita entre los individuos, quienes de este modo son partes de una forma de cosmopolitismo.

Si se generalizan los conceptos de una Unión Europea y de una república mundial de carácter federal, obtenemos nuevas formas de integración interestatal en la que se unen diferentes estratos históricos (Lübbe 2005, p. 94; Cheneval 2005, p. 181). El lugar del antiguo modelo unitario de Estado con sus hegemonías lo ocupa ahora el modelo del Estado consociativo o policéntrico que se distingue en términos funcionales y territoriales. Esto conduce a una incongruencia territorial en el ámbito interestatal para una diferenciación funcional y una territorialidad en varios niveles. Los Estados se han desplazado de lugar y han vuelto a conectar de manera incongruente elementos importantes de la estatalidad moderna (Cheneval 2005, p. 197). Los Estados otorgan tareas y competencias que se definen en términos funcionales a instituciones intergubernamentales y supranacionales.

Esto tiene como consecuencia para la estructura de la historia la formación de órdenes espaciales y temporales entremezclados (Hardt y Negri 2001, pp. 137, 316; Sassen 2008, p. 607). Surge la experiencia de un espacio-tiempo transnacional. Lo espacial y lo temporal ya no se sitúan fuera de lo nacional, sino que se encuentran integrados en lo nacional mediante interdependencias complejas. Es así como aparecen los ensamblajes espacio-temporales como una nueva forma de territorialidad (Sassen 2008, p. 621).

Para resumir el debate sobre la globalización se pueden citar dos modelos extremos y un modelo mediador. El punto de vista global se expresa en el modelo de un "sistema capitalista mundial" (Wallerstein 1988; Altvater y Mahnkopf 1996, pp. 120 y ss.). En conexión con los descubrimientos coloniales de la Modernidad temprana, así como con las experiencias de un mercado mundial en expansión y de una división internacional del trabajo, este punto de vista presupone un mercado único con diferentes centros, periferias y semiperiferias. La perspectiva local se muestra en el modelo de una "política, técnica y cultura policéntricas", en la que lo local recupera su sentido (Rosenau 1990, pp. 32-33; Beck 1997, pp. 67 y ss.; Menzel 1998, pp. 40 y ss.). Tras la 
despolitización de los Estados nacionales, ha surgido una subpolítica en numerosos centros; por ejemplo, en las organizaciones transnacionales, los movimientos de boicots, entre otros. Incluso los nuevos medios de comunicación contribuyen a la descentralización y relocalización. Por último, como mediador tenemos el modelo de la "glocalización", en el que lo "global" y lo "local" se traslapan (Robertson 1992, pp. 173174; Giddens 2005, p. 62; Pohlmann 2006, p. 165). La interpretación detrás de esta posición es que en los debates la globalización y la localización se han considerado opuestos falsos. Del mismo modo que no puede afirmarse que la globalización conduzca necesariamente a la homogeneización, tampoco se puede sostener que lo local contradiga lo global. Así, lo universal y lo particular no se excluyen, sino que las tendencias homogeneizantes y heterogeneizantes se entretejen en forma recíproca.

Desde la perspectiva de la teoría de sistemas lo esencial de esta tendencia opuesta consiste en que la sociedad mundial, analizada como un sistema social, produce sus diferenciaciones, particularidades y localizaciones como consecuencias propias (Luhmann 1997, pp. 162-163). No obstante, de ahí se sigue que lo global y lo local no se pueden representar como una relación simétrica. Es más bien la globalización la que causa, en parte, efectos localizadores. Esto se aplica también a las consecuencias negativas que provocan que un gran número de pueblos y naciones, e incluso partes enteras del planeta, queden fuera de la globalización. Estas exclusiones tienen como consecuencia un hecho ya bien diagnosticado y que ha levantado numerosas protestas: el dramático crecimiento de la pobreza global. Las desigualdades que han surgido así no son reliquias de una prehistoria de la globalización, sino resultados del sistema técnico-económico actual de carácter mundial.

\section{Responsabilidad global en el contexto histórico}

$\mathrm{Si}$ se prescinde de posiciones liberales y nacionalistas extremas, hay un consenso en que las personas que viven en los países ricos están obligadas a aliviar el sufrimiento de los necesitados en los países pobres. Esto se aplica sobre todo a los Estados en todo el mundo. Es verdad que pueden establecerse diferencias entre determinados grados de deberes de auxilio al fijar obligaciones particulares con los miembros de una familia o con los miembros de la propia nación, de lo cual se deriva una concepción escalonada de la justicia (Walzer 1999, p. 38; Zurbuchen 2005, p. 139; Nida-Rümelin y Rechenauer 2009, pp. 314, 319). Sin 
embargo, de ahí no se sigue que otros deberes más amplios respecto de las personas que habitan en regiones alejadas carezcan de justificación. Asimismo, la objeción de que este tipo de redistribución de bienes entre los países ricos y los pobres presupone un "Estado mundial" que, una vez más, encierra el peligro del abuso (Nusser 1997, p. 92) no es convincente porque, como ya se señaló, hay también Estados individuales y organizaciones transatlánticas capacitadas para participar en esa tarea.

La pregunta que surge aquí es por qué motivos los seres humanos están obligados a ayudar a sus semejantes. Y en este punto hay respuestas encontradas.

Por un lado, la posición de la llamada "obligación de ayudar" (obligation to assist) de Peter Singer se basa en el argumento de que los seres humanos como tales están obligados a socorrer a otros seres humanos siempre y cuando les sea posible. Para ello las antiguas cooperaciones o incluso las vinculaciones históricas entre las personas afectadas no deben tener relevancia alguna. Intentaré mostrar que el deber abstracto de prestar ayuda humanitaria es incapaz de responder la pregunta sobre la motivación.

Por otro lado, la posición de la "responsabilidad por las consecuencias" (outcome responsibility) de Thomas Pogge parte de que la situación de emergencia de los individuos en los países pobres ha de comprenderse como una "consecuencia" de las acciones de los habitantes de los países ricos o poderosos. Aquí entra en escena el aspecto histórico, ya que esta responsabilidad por las consecuencias se fundamenta en un proceso histórico que otrora condujo a grandes desigualdades. Mi tesis es que la responsabilidad global con las personas y con los pueblos tratados injustamente requiere, una vez más, una reflexión desde la historia y desde la filosofía de la historia.

Si nos fijamos con mayor detenimiento en la argumentación sobre la obligación de ayudar, encontraremos un lugar paradójico para la historia. Una de las razones es que el sufrimiento y la muerte de las personas se considera algo esencialmente malo y que tendría que superarse en cada caso sin necesidad de establecer una relación histórico-práctica entre aquellos que ofrecen su ayuda y aquellos que la buscan (Singer 1972, p. 231; Schlothfeldt 2007, p. 77; Schaber 2007, p. 139). Quienes están obligados a ayudar actúan como testigos capacitados, pero que observan desde la distancia a quienes sufren carencias. Como, a fin de cuentas, se trata de un principio antropológico y, por lo tanto, de la unidad del género humano, la obligación de ayudar es aquí un cosmopolitismo abstracto. Un razonamiento similar ofrece el argumento 
metaético basado en una moral universalista que pide desde un punto de vista imparcial la aprobación general para la norma moral de prestar auxilio (Birnbacher 2007, p. 139). De ahí que, en consecuencia, la comunidad moral de carácter global asuma del modo más eficiente posible la responsabilidad por el bienestar de todos los hombres, cuyo nivel de vida no debe ser menor al mínimo vital.

Otro razonamiento dice que los hombres están obligados a impedir o paliar el sufrimiento, independientemente de cómo haya surgido, siempre que esté en su mano poder hacerlo. El límite pragmático consiste en que la obligación de ayudar se circunscribe a impedir lo malo, y no a fomentar lo bueno, por lo que no se pueden exigir demasiados sacrificios. En este argumento aparece de nuevo la historia de una manera encubierta, ya que el poder de ayudar también a las personas que habitan en países lejanos depende esencialmente del desarrollo de los medios técnicos de comunicación y de transporte (Singer 1972, p. 232). En esto consisten las condiciones de posibilidad reales para el deber global de auxilio y, dado que estas condiciones sufren transformaciones en el transcurso de la historia, la posición de la obligación de ayudar adquiere una dimensión histórica inesperada. Frente a la ética tradicional, que se limita al estrecho círculo de la familia, la región o el Estado nacional, surge ahora una nueva ética del deber global de auxilio.

Este argumento también podría formularse de la siguiente manera: puesto que las personas disponen de nuevos medios técnicos para poder ayudar a las personas que habitan en lugares muy alejados, están obligadas a prestar esta ayuda. Al suponer que mitigar el sufrimiento es, por lo general, algo deseable, no se incurre en falacia naturalista alguna. Lo que se pone de manifiesto es, más bien, el conocimiento de que los nuevos instrumentos técnicos inducen a nuevos objetivos morales o a normas condicionadas históricamente, lo que desemboca en una transformación de los valores mediada por la técnica. Según esta posición, lo histórico no remite a la prehistoria del destino de quienes sufren carencias, sino al poder histórico actual que han desarrollado los que ayudan.

Con la segunda posición de la responsabilidad por las consecuencias se plantea la pregunta de si es suficiente con la fundamentación de la mera obligación de ayudar y si, a su vez, no pueden justificarse otras obligaciones más amplias.

Por el lado de los que asisten, el problema consiste en los sujetos que están obligados a ayudar. Aquí da la impresión de que hay individuos que deciden ofrecer ayuda sin que, en principio, exista un acuerdo mutuo. Falta también una diferenciación social de los ricos y una clasificación de los sistemas sociales. A este planteamiento se le ha de objetar 
que en las acciones globales de ayuda los actores colectivos tienen mucha más importancia de lo que parece. Incluso un llamado para hacer donativos, ante el cual los individuos reaccionan en forma espontánea, se trata de una acción coordinada (Schlothfeldt 2007, p. 77). Esto se aplica aun en mayor medida en el caso de los Estados y las organizaciones transatlánticas que funcionan como instituciones sociales.

Por parte de los que requieren ayuda surge la dificultad de que aparecen como meras víctimas. Siguen siendo víctimas pasivas y anónimas, extraños morales, para quienes no existe ninguna relación especial de responsabilidad (Birnbacher 2007, p. 132). Figuran sólo como objetos de un auxilio que encierra en sí mismo el peligro de lo autoritario y lo arbitrario. Lo que llama la atención sobre todo es que, aunque a los ricos se les asignen determinadas obligaciones, a los pobres no se les asigna ningún derecho. A las obligaciones no les corresponde ningún derecho que pueda ser válido como reivindicación legítima. Se requiere en especial una interacción previa entre los que dan y los que reciben. De este modo se eliminan también todos los criterios de una justicia distributiva.

$\mathrm{Si}$, por el contrario, insistimos en que los pobres tienen derechos que van más allá de los derechos humanos universales, nos remitiremos a contextos concretos relacionados con una desigualdad social que debe resolverse o, al menos, corregirse. A menudo se habla aquí de una cooperación que puede dar como resultado un compromiso global (Nida-Rümelin y Rechenauer 2009, p. 316). En contraste, quien caracteriza la interacción con los pobres como cooperación (Birnbacher 2007, p. 135) puede hablar de manera neutral de un contexto de acción que incluye desde la discriminación hasta la explotación de pueblos extranjeros. La cooperación positiva o negativa constituye los fundamentos de una responsabilidad moral de las ricas naciones industriales con los países pobres en vías de desarrollo.

De este estado de cosas resultan obligaciones que van más allá de la pura obligación de ayudar. Es verdad que los ciudadanos y los Estados ricos tienen el deber moral positivo de ayudar a las personas que se encuentran en una situación de pobreza que amenaza su propia vida; sin embargo, tienen al mismo tiempo el deber negativo de minimizar los daños que ellos mismos han provocado (Pogge 2010, p. 10). Como el orden mundial no es justo, los pobres tienen que ser compensados por los perjuicios que sufren. Este tipo de compensación no es una ayuda, sino una mitigación de los daños; no es una redistribución entre ricos y pobres, sino la corrección de una estructura social desigual entre ricos y pobres. No ayudar a los desfavorecidos es menos reprobable 
que privarlos de sus beneficios legítimos aprovechando su situación de desventaja (Pogge 2010, p. 11).

Esta concepción de la responsabilidad por las consecuencias tiene implicaciones históricas, por eso me gustaría hablar también de una responsabilidad histórica. La razón es que tras esta argumentación se esconde la idea de que la pobreza mundial es consecuencia de un proceso histórico, desde la colonización, la esclavización, el genocidio y la explotación (Pogge 2010, p. 222). Ahora bien, si nos limitamos a la mera prestación de auxilio, pasaremos por alto que la enorme superioridad económica de Occidente tiene sus raíces en los siglos de historia común (Nida-Rümelin y Rechenauer 2009, p. 300). La mayor parte de los derechos de propiedad ha surgido inaceptablemente mediante la violencia, la conquista y la represión. De ahí se deriva la exigencia de reclamar deberes más amplios para compensar la injusticia sufrida. Aquí se aplica el principio jurídico de la responsabilidad por culpa: quien ha puesto a alguien en dificultades mediante la acción positiva es responsable de su reparación; provocar un mal genera un alto grado de responsabilidad.

Justo contra este argumento histórico hay una serie de objeciones. Al parecer, el alcance de la obligación de compensar es sólo limitado. Por un lado, esta obligación presupone que realmente se pueden probar los daños y perjuicios causados con anterioridad. Por otro lado, se debe demostrar que los perjuicios del pasado aún tienen efecto en el presente. Primero se objeta que los gobiernos actuales en los países en vías de desarrollo son como mínimo igual de responsables de la pobreza actual que los antiguos colonialistas. Además, la obligación de compensar el comportamiento dañino se aplica sólo a los Estados que, en una etapa anterior, estaban realmente involucrados en la injusticia cometida (Birnbacher 2007, p. 136). Por último, existe el problema de determinar los sujetos morales cuando se considera que sólo los individuos particulares son los que han de rendir cuentas, y se deja fuera a los actores colectivos.

Una objeción especialmente extendida es la de las llamadas causas internas, que sostiene que los factores esenciales de la pobreza global están en los países que en la actualidad se encuentran en vías de desarrollo y, por lo tanto, en las dificultades estatales internas. Esto parece indicar que entre los países en vías de desarrollo existen diferencias considerables causadas por factores locales, así que, a fin de cuentas, es el conjunto de los factores locales lo que provoca la pobreza global (Pogge 2010, p. 11; Rawls 1999, p. 134; Nagel 2005, p. 123). Esto parece confirmarse por la frecuencia con la que se suceden los gobiernos brutales y corruptos en los países en vías de desarrollo de hoy en día. 
Por el contrario, los éxitos de algunos países emergentes y en vías de desarrollo parecen demostrar que, entretanto, los efectos dañinos de la antigua colonización tienden a desaparecer. Aparte del hecho de que la tesis de las "causas internas" sirve de coartada para los países ricos, no se puede pasar por alto que una impresión como ésta ha podido originarse porque los historiadores y científicos sociales se centran más en los factores nacionales y regionales que en el desarrollo mundial.

No obstante, la obligación de compensar ha de justificarse en el hecho de que las circunstancias locales no ofrecen una explicación suficiente para la pobreza global. El orden económico mundial con sus injusticias es aún responsable de que la economía nacional de los países en vías de desarrollo no pueda prosperar. De ahí que África no tenga hoy en día ninguna posibilidad de recuperar la ventaja que le lleva Europa, que es de una proporción de 30 a 1, ni siquiera con un crecimiento económico continuo. Si se tiene en cuenta esta disparidad, no se debe considerar que la desigualdad actual sea simplemente resultado de una libre elección. A esto hay que añadir que incluso los llamados "factores intraestatales" también están condicionados por el orden global, ya que el orden mundial actual contribuye en gran medida a la corrupción y a la opresión en los países en vías de desarrollo (Pogge 2010, p. 15). Aquí se incluye el privilegio internacional de las materias primas, la desproporción en la riqueza de recursos y en el crecimiento económico, así como la dependencia del espacio global (Pogge 2010, p. 19; Kesselring 2005, p. 48). La consecuencia de todo esto es que lo relevante no es nada más una distribución justa, sino también, y sobre todo, la eliminación de las condiciones injustas de producción.

No es menos importante rechazar la falacia según la cual la obligación de compensar pondría en cuestión la obligación de ayudar, como si ambos tipos de obligaciones se excluyesen entre sí. Desde luego, todos los países ricos están obligados a ayudar, incluso si no se sienten culpables o no aceptan la concepción de la responsabilidad por las consecuencias. Pero el argumento colateral sostiene que los Estados que en el pasado cometieron alguna injusticia están especialmente obligados a ofrecer compensaciones en el presente.

En todos estos debates se puede apreciar la relevancia del componente histórico, porque detrás se encuentra la idea de que la pobreza global la han "hecho" determinadas personas a lo largo de la historia. Precisamente en esta forma de "hacer" de la historia es donde se desarrolla la disputa. En este punto incluso los detalles históricos desempeñan un papel en la determinación de cuáles son los factores locales y globales que se deben ponderar, y en qué medida y con qué alcance espacial 
y temporal se ha de llevar a cabo esta ponderación. Aquí se ofrece todo el arsenal de la investigación histórica, incluidas las cuestiones metodológicas sobre las funciones explicativas de los datos. Se pone así de manifiesto que recurrir a "causas" individuales no es en absoluto suficiente para "aclarar" ciertos fenómenos, sino que se trata en cada caso de estructuras complejas de condiciones de posibilidad. Incluso el procedimiento de explicaciones contrafácticas entra en escena cuando se discute si, por ejemplo, a las personas de los países en vías de desarrollo no les iría hoy mejor si hubiesen permanecido en un estado de naturaleza ficticio y las colonizaciones no hubiesen tenido lugar (Pogge 2010, p. 20).

Por último está la cuestión pragmática de en qué medida la referencia al pasado conduce a contribuciones compensatorias cuantificables (Rohbeck 2013, pp. 180 y ss.; Rohbeck 2012, pp. 151 y ss.). No cabe duda de que todos los intentos por satisfacer las demandas mencionadas no han encontrado hasta ahora más que dificultades casi insuperables. En cuanto a las ayudas realmente prestadas, están lejos de representar un terreno práctico en el que la diferencia teórica entre la obligación de ayudar y los deberes por las consecuencias desempeñe algún papel. El concepto de responsabilidad histórica es, pues, no tanto una estrategia practicable, sino un postulado normativo.

Sin embargo, la dimensión histórica es importante, porque recurrir a la historia puede producir un efecto simbólico. Este recurso implica pagos que, aunque no son propiamente compensaciones, sí pueden entenderse como un reconocimiento parcial de la injusticia sufrida. A esto se une de manera evidente el propósito de reforzar la conciencia de una responsabilidad histórica especial. Aunque esta argumentación no se refleje de manera inmediata en las cifras adecuadas, puede contribuir a hacer por los países pobres más de lo que se está obligado en una situación puntual. En particular, el argumento histórico exige no sólo mitigar el sufrimiento, sino también combatir sus causas y apostar por un orden mundial más equitativo que el que se ha desarrollado en el transcurso de la historia. Esto plantea la tarea de mirar hacia el futuro para buscar posibilidades alternativas de desarrollos globales.

\section{Conclusión}

La mayoría de los pensadores que reflexionan sobre cuestiones éticas y se ocupan del problema de la pobreza global descuidan la dimensión histórica a la hora de analizar este problema. Esta falta de historicidad encierra una dificultad doble. Por una parte, la fundamentación de 
los principios universales no es suficiente para la obligación de ayudar que se toma en consideración. Por otra parte, estos principios son tan abstractos que se carece de una diferenciación tanto de los necesitados como de los que están obligados a prestar ayuda. La lucha contra la pobreza global no debe confundirse con el universalismo. Por el contrario, adoptar la perspectiva ética global supone analizar el proceso histórico de la globalización y derivar las responsabilidades concretas y diferenciadas de las condiciones que originaron la pobreza global.

Como ya vimos, el proceso de globalización se desarrolla en diversos espacios y tiempos históricos. En el ámbito de la economía mundial esto significa que hay que tener presente las nuevas economías regionales capitalistas, incluida la explotación de recursos naturales, la expansión de los mercados de consumo y la búsqueda de condiciones de producción rentables en países alejados. Si bien al realizar una comparación internacional también es legítimo hacer referencia a los factores locales, esto no nos debe inducir a subestimar las influencias del sistema económico mundial. En el terreno de la política esto significa que se debe diferenciar el papel de cada uno de los Estados nacionales, y esto se aplica sobre todo a los países en vías de desarrollo que de una manera específica fueron dependientes de los antiguos poderes coloniales, y que incluso aún lo son. Por lo tanto, cuando se hace referencia a las fallas de estos Estados para culpabilizarlos por la pobreza global, hay que señalar también que los déficits intraestatales no están condicionados en menor medida por el orden global. Para superar la miseria, surgen alianzas estatales en grupos de países emergentes y en vías de desarrollo que cumplen una función similar a la de la Unión Europea. También en estos casos se traslapan los planos nacionales y transnacionales, lo que da lugar a una configuración espacio-temporal de carácter supraterritorial. Justo estos nuevos ensamblajes requieren del apoyo especial de las antiguas naciones industriales.

Así, enfocar la atención en la historia de la globalización muestra que ya no sólo tenemos que preguntar de manera general por los inicios históricos de este proceso, sino que hay que investigar con mayor detalle dónde y cuándo han de buscarse las raíces de la pobreza global. Si se coloca esta pregunta en primer plano, el inicio de la globalización se deberá situar de seguro en otros tiempos. De hecho, si no es que en las primeras fases de la colonización, entre los siglos XVI y XVIII, sí que se podría situar en el colonialismo del siglo XIX. Y, si el surgimiento de las redes electrónicas en el siglo xx explica el nacimiento de la globalización moderna, se debe preguntar aquí en qué medida estas redes fomentan o impiden el desarrollo en los países pobres. Sigue siendo 
incuestionable que, en efecto, hay regiones enteras que se ven perjudicadas o excluidas con este desarrollo.

Por último, las consecuencias a largo plazo que estos desarrollos tendrán en las condiciones de vida de los países pobres plantean la pregunta, propia de la filosofía de la historia, por las continuidades y discontinuidades en el proceso de la globalización. Es obvio que el postulado de una responsabilidad histórica sólo es posible cuando se presupone un mínimo de continuidad histórica; quienes absolutizan las rupturas en el proceso de globalización corren el peligro de subestimar las consecuencias a largo plazo y jugar así a favor de los que niegan una responsabilidad histórica. Aferrarse a un desarrollo continuo no significa en absoluto creer de manera ingenua en un proceso lineal de modernización o en un progreso homogéneo. Es muy probable que la declaración a favor de una historia responsable y la crítica a los aspectos negativos del desarrollo histórico sean compatibles. A fin de cuentas, la lucha contra la pobreza global parte de la convicción de que las condiciones de vida se pueden mejorar a largo plazo. No sólo los pobres del mundo podrían considerar estas mejoras como "progreso", sino que, sin esta idea regulativa, ni siquiera es posible imaginar una ética de la responsabilidad global. En estas convicciones queda de manifiesto la importancia de los modelos de interpretación de la historia y la medida en que es indispensable la reflexión sobre la globalización desde la historia y la filosofía de la historia.

[Traducción del alemán: Manuel Orozco Pérez]

\section{BIBLIOGRAFÍA}

Acha, O., 2016, "Travesías de la 'historia mundial' a la 'historia global' en perspectiva latinoamericana: apuntes de investigación", en D. Brauer (comp.), La historia en tiempos de globalización, Prometeo, Buenos Aires, pp. 167-194.

Altvater, E. y B. Mahnkopf, 1996, Grenzen der Globalisierung. Ökonomie, Ökologie und Politik in der Weltgesellschaft, Westfälisches Dampfboot, Münster.

Antweiler, Ch., 2011, Mensch und Weltkultur. Für einen realistischen Kosmopolitismus im Zeitalter der Globalisierung, Transcript, Bielefeld.

Baudrillard, J., 2007, "Vom Universellen zum Singulären: die Gewalt des Globalen", en J. Bindé (comp.), Die Zukunft der Werte. Dialoge über das 21. Jahrhundert, trad. F. Sievers y A. Jandl, Suhrkamp, Fráncfort del Meno/Berlín, pp. 36-45.

Beck, U., 1997, Was ist Globalisierung?: Irrtümer des Globalismus, Antworten auf Globalisierung, Suhrkamp, Fráncfort del Meno. 
Belvedresi, R.E., 2012, "Global History and the Idea of Universal History", en G. Lottes et al. (comps.), New Perspectives in Global History, Wehrhahn, Hannover, pp. 63-70.

Birnbacher, D., 2007, "Die ethischen Grundlagen globaler Hilfspflichten", en K. Schüttauf y G. Brudermüller (comps.), Globalisierung - Probleme einer neuen Weltordnung, Königshausen und Neumann, Wurzburgo, pp. 131-148.

Brauer, D., 2016, "La historia globalizada. ¿El retorno del Weltgeist?", en D. Brauer (comp.), La historia en tiempos de globalización, Prometeo, Buenos Aires, pp. 51-65.

Cheneval, F., 2005, "Zwischenstaatliche Integration als Vorbild neuer Weltordnung", en E. Angehrn y B. Baertschi (comps.), Globale Gerechtigkeit und Weltordnung. Justice globale et ordre mondial, Schwabe, Basilea, pp. 179201.

D'Aprile, I.-M., 2012, "Critical Global Studies and Planetary History. New Perspectives on the Enlightenment", en G. Lottes et al. (comps.), New Perspectives in Global History, Wehrhahn, Hannover, pp. 123-134.

Darwin, J., 2009, After Tamerlane: The Global History of Empire since 1405, Bloomsbury, Londres.

Figueroa, D., 2004, Philosophie und Globalisierung, Königshausen und Neumann, Wurzburgo.

Giddens, A., 2005, "The Globalizing of Modernity", en D. Held y A. McGrew (comps.), The Global Transformations Reader. An Introduction to the Globalization Debate, 2a. ed., Polity, Cambridge, Mass., pp. 60-66.

Groß, S.W., 2007, "Kulturelle Mannigfaltigkeit und 'Globalisierung'. Heterogenität und Konnexion", en K. Schüttauf y G. Brudermüller (comps.), Globalisierung - Probleme einer neuen Weltordnung, Königshausen und Neumann, Wurzburgo, pp. 11-28.

Habermas, J., 2011, Zur Verfassung Europas. Ein Essay, Suhrkamp, Berlín.

Hardt, M. y A. Negri, 2001, Empire, Harvard University Press, Cambridge, Mass.

Harvey, D., 2003, The New Imperialism, Oxford University Press, Oxford.

Haug, W.F., 2003, High-Tech-Kapitalismus. Analysen zu Produktionsweise, Arbeit, Sexualität, Krieg \& Hegemonie, Argument, Hamburgo.

Hegel, G.W.F., 1970, Werke in 20 Bänden, vol. 12, Vorlesungen über die Philosophie der Geschichte, ed. E. Moldenhauer y K.M. Michel, Suhrkamp, Fráncfort del Meno.

Hirst, P. y G. Thompson, 2005, "Globalization - A Necessary Myth?", en D. Held y A. McGrew (comps.), The Global Transformations Reader. An Introduction to the Globalization Debate, 2a. ed., Polity, Cambridge, Mass., pp. 98-105.

Höffe, O., 1999, Demokratie im Zeitalter der Globalisierung, C.H. Beck, Múnich. Jameson, F., 1998, "Notes on Globalization as a Philosophical Issue", en F. Jameson y M. Masao (comps.), The Cultures of Globalization, Duke University Press, Londres, pp. 54-77.

Diánoia, vol. LXIII, no. 80 (mayo de 2018). 
Keohane, R.O. y J.S. Nye, 2005, “Globalization: What's New? What's Not? (And So What?)", en D. Held y A. McGrew (comps.), The Global Transformations Reader. An Introduction to the Globalization Debate, 2a. ed., Polity, Cambridge, Mass., pp. 75-83.

Kesselring, Th., 2005, "Internationale Gerechtigkeit. Auf der Suche nach Kriterien”, en E. Angehrn y B. Baertschi (comps.), Globale Gerechtigkeit und Weltordnung. Justice globale et ordre mondial, Schwabe, Basilea, pp. 23-53.

Kohler, G., 2005, "Hobbes und das 21. Jahrhundert. Zum Problem des Politischen Realismus", en E. Angehrn y B. Baertschi (comps.), Globale Gerechtigkeit und Weltordnung. Justice globale et ordre mondial, Schwabe, Basilea, pp. 159-179.

Koselleck, R., 1979, Vergangene Zukunft. Zur Semantik geschichtlicher Zeiten, Suhrkamp, Fráncfort del Meno.

—_, 2000, "Raum und Geschichte", en R. Koselleck, Zeitschichten. Studien zur Historik, Suhrkamp, Fráncfort del Meno, pp. 78-96.

Lübbe, H., 2005, Die Zivilisationsökumene. Globalisierung kulturell, technisch und politisch, Wilhelm Fink, Múnich.

Luhmann, N., 1997, Die Gesellschaft der Gesellschaft, vol. I, Suhrkamp, Fráncfort del Meno.

Marx, K. y F. Engels, 1958, Die deutsche Ideologie, en Marx Engels Werke, vol. 3, 1845 bis 1846, Dietz, Berlín, pp. 13-530.

McLuhan, M., 1995, Die magischen Kanäle. Understanding Media, Verlag der Kunst, Dresde/Basilea.

McNeill, W.H., 1982, "A Defense of World History", Transactions of the Royal Historical Society, serie 5, vol. 32, pp. 75-92.

Menzel, U., 1998, Globalisierung versus Fragmentierung, Suhrkamp, Fráncfort del Meno.

Nagel, Th., 2005, "The Problem of Global Justice", Philosophy and Public Affairs, vol. 33, no. 2, pp. 113-147.

Negt, O., 2001, Arbeit und menschliche Würde, Steidl, Gotinga.

Nida-Rümelin, J. y M. Rechenauer, 2009, "Internationale Gerechtigkeit", en M.A. Ferdowsi (comp.), Internationale Politik als Überlebensstrategie, Bayerische Landeszentrale für politische Bildungsarbeit, Múnich, pp. 297-321.

Nusser, K.-H., 1997, "Kosmopolitische Vernunft und globale Weltordnung", en N. Brieskorn (comp.), Globale Solidarität, Kohlhammer, Stuttgart, pp. 89-104.

Osterhammel, J., 1998, "Die Wiederkehr des Raumes: Geopolitik, Geohistorie und historische Geographie", Neue Politische Literatur, vol. 43, no. 3, pp. 374-395.

Pogge, Th., 2010, Politics as Usual: What Lies Behind the Pro-Poor Rhetoric?, Polity, Cambridge.

Pohlmann, M., 2006, "Globalisierung und Modernisierung - Zentrale Annahmen der Globalisierungstheorien auf dem Prüfstand", en Th. Schwinn (comp.), Die Vielfalt und Einheit der Moderne: Kultur- und strukturvergleichende Analysen, VS, Wiesbaden, pp. 165-183. 
Rawls, J., 1999, The Law of Peoples, Harvard University Press, Cambridge, Mass. Raynal, G. y D. Diderot, 2001, Histoire philosophique et politique des établissements et du commerce des européens dans les deux Indes, ed. Y. Bénot, La Découverte, París.

Ricœur, P., 1983, Temps et récit, vol. I, Le Seuil, París.

Robertson, R., 1992, Globalization: Social Theorie and Global Culture, Sage, Londres.

Rohbeck, J., 2000, Technik. Kultur. Geschichte. Eine Rehabilitierung der Geschichtsphilosophie, Suhrkamp, Fráncfort del Meno.

__, 2010, Aufklärung und Geschichte: Über eine praktische Geschichtsphilosophie der Zukunft, Akademie, Berlín.

—, 2012 , "Filosofía de la historia y ética del futuro", en F. Birulés, A. Gómez Ramos y C. Roldán (comps.), Vivir para pensar. Ensayos en homenaje a Manuel Cruz, Herder, Barcelona, pp. 151-166.

—_, 2013, Zukunft der Geschichte. Geschichtsphilosophie und Zukunftsethik, De Gruyter, Berlín.

Roldán, C., 2012, "Enlightenment, Philosophy of History and Values: European Roots of Universalism", en G. Lottes et al. (comps.), New Perspectives in Global History, Wehrhahn, Hannover, pp. 83-96.

Rosenau, J., 1990, Turbulence in World Politics, Prentice Hall, Brighton.

Sassen, S., 2008, Das Paradox des Nationalen. Territorium, Autorität und Rechte im globalen Zeitalter, Suhrkamp, Fráncfort del Meno.

Schaber, P., 2007, "Globale Hilfspflichten", en B. Bleich y P. Schaber (comps.), Weltarmut und Ethik, Mentis, Paderborn, pp. 139-151.

Schlögel, K., 2003, Im Raume lesen wir die Zeit. Über Zivilisationsgeschichte und Geopolitik, Fischer, Múnich/Viena.

Schlothfeldt, S., 2007, "Wer ist der Weltarmut wozu verpflichtet?", en B. Bleich y P. Schaber (comps.), Weltarmut und Ethik, Mentis, Paderborn, pp. 77-93.

Schlözer, A.L. von, 1772, Universalhistorie, Bey Johann Christian Dieterich, Gotinga.

Scholte, J.A., 2005, Globalization. A Critical Introduction, 2a. ed., Macmillan, Nueva York.

Singer, P., 1972, "Famine, Affluence and Morality", Philosophy and Public Affairs, vol. 1, no. 3, pp. 229-243.

Toulmin, S., 1994, Kosmopolis. Die unerkannten Aufgaben der Moderne, Suhrkamp, Fráncfort del Meno.

Touraine, A., 2007, "Für einen Wiederaufbau der Kultur", en J. Bindé (comp.), Die Zukunft der Werte. Dialoge über das 21. Jahrhundert, trad. F. Sievers y A. Jandl, Suhrkamp, Fráncfort del Meno/Berlín, pp. 245-253.

Turgot, A.R.J., 1913, "Plan de deux discours sur l'histoire universelle", en CEuvres de Turgot et documents le concernant, vol. I, Turgot étudiant et magistrat, 1743-1761, ed. G. Schelle, Alcan, París, pp. 275-323.

Virilio, P., 1990, L'Inertie polaire, Christian Bourgeois, París.

Wallerstein, I., 1988, One World, Many Worlds, Pearson, Nueva York.

Diánoia, vol. LXIII, no. 80 (mayo de 2018). 
Walzer, M., 1999, “Zur Erfahrung von Universalität”, en K.-J. Kuschel, A. Pinzani y M. Zillinger (comps.), Ein Ethos für eine Welt? Globalisierung als ethische Herausforderung, Campus, Fráncfort del Meno/Nueva York, pp. 38-47.

Zurbuchen, S., 2005, "Globale Gerechtigkeit und das Problem der kulturellen Differenz-Eine kritische Auseinandersetzung mit dem liberalen Nationalismus", en E. Angehrn y B. Baertschi (comps.), Globale Gerechtigkeit und Weltordnung. Justice globale et ordre mondial, Schwabe, Basilea, pp. 121-141.

Recibido el 17 de enero de 2017; revisado el 24 de abril de 2017; aceptado el 10 de agosto de 2017. 